\title{
Molecular variation in relation to purine metabolism
}

\author{
R. W. E. WATTS \\ From the Division of Inherited Metabolic Diseases, MRC Clinical Research Centre, Harrow, Middlesex
}

The disorders of purine metabolism illustrate the causation of human disease by molecular variants in the sense of different abnormal enzymes producing the same clinico-pathological manifestations and of different inherited anomalies of the same enzyme protein resulting in the same clinical manifestations. Except for the clinical recognition of tophaceous gout and uric acid urinary stones, an abnormal concentration of uric acid in the blood or urine is the usual indicator of an abnormality in this area of metabolism, and the serum uric acid is usually measured in routine biochemical profiles. The methods of measuring uric acid in biological fluids were recently reviewed by Watts (1974a). Those based on the reduction of phosphotungstate or arsenophosphotungstate solutions are liable to interference by other reducing agents, and these errors are particularly important in the analysis of urine. Methods depending on the high specificity of the uricase (urate : oxygen oxidoreductase EC 1.7.3.3) catalyzed oxidation of uric acid are preferred.

\section{Biochemistry and Physiology}

\section{PURINE BIOSYNTHESIS DE NOVO}

Purines are derived either from the diet or synthesized, mainly in the liver, from small molecular precursors. The biosynthetic source of the individual atoms of the purine ring and the steps in the biosynthetic sequence are shown in figures 1 and 2 respectively. The formation of $\beta$-phosphoribosylamine from $\alpha$-5-phospho- $D$-ribosyl-1-pyrophosphate ('phosphoribosylpyrophosphate' or 'PRPP') and glutamine is the first reaction which is specific to purine biosynthesis. It is catalysed by phosphoribosylpyrophosphate amidotransferase [ribosylamine-5'-phosphate pyrophosphate phosphoribosyltransferase (glutamate amidating) EC 2.4.2.14] and is the rate-limiting step on the metabolic pathway. Variations in the activity of this reaction are brought about by the availability of PRPP and through a series of feedback controls by the purine ribonucleotides which are the end products of the biosynthetic sequence. Recent evidence indicates that these factors operate by altering the subunit structure of the enzyme, PRPP converting the enzyme to the catalytically active monomeric form (molecular weight 133000 ), and purine ribonucleotide promoting aggregation of the enzyme subunits into a dimeric form (molecular weight 270000 ) which is catalytically inactive. Mammalian liver is a relatively poor starting material for the preparation of phosphoribosyl amidotransferase and the catalytic and kinetic properties of the enzyme were studied in detail by Holmes and his colleagues (Holmes, McDonald, McCord, Wyngaarden, and Kelley, 1973; Holmes, Wyngaarden, and Kelley, 1973) using enzyme isolated from human placenta. These studies extended results of earlier investigations on the pigeon liver enzyme (Caskey, Ashton, and Wyngaarden, 1964; Rowe and Wyngaarden, 1968; Rowe, Coleman, and Wyngaarden, 1970). The recently reported properties of human glutamine phosphoribosylpyrophosphate amidotransferase are presented in table I. Wood and Seegmiller (1973) studied the phosphoribosylpyrophosphate amidotransferase activity of extracts from human lymphoblasts and report that PRPP and purine ribonucleotides compete with one another for binding to the enzyme.

The intracellular concentration of PRPP influences the rate of purine biosynthesis de novo. Orotic acid and nicotinic acid combine with PRPP under the influence of specific phosphoribosyltransferases in cultured fibroblasts. This lowers the intracellular concentration of PRPP and is associated with a reduced rate of purine biosynthesis de novo (Fox, Wyngaarden, and Kelley, 1970; Kelley, Fox, and Wyngaarden, 1970; Boyle, Raivio, Becker, and Seegmiller, 1972). Conversely, increasing the PRPP level in cultured fibroblasts by adding methylene blue increases the rate of purine synthesis de novo by the cells. Methylene blue accelerates NADP ${ }^{+}$ regeneration from NADPH and increases glucose oxidation thereby stimulating the production of ribose-5-phosphate (R5P). Glucose, fructose, and mannose increase purine biosynthesis de novo in vitro (Henderson and Khoo, 1965; Greene and Seegmiller, 1969), and the acute administration of fructose, galactose, mannose or glucose produces 


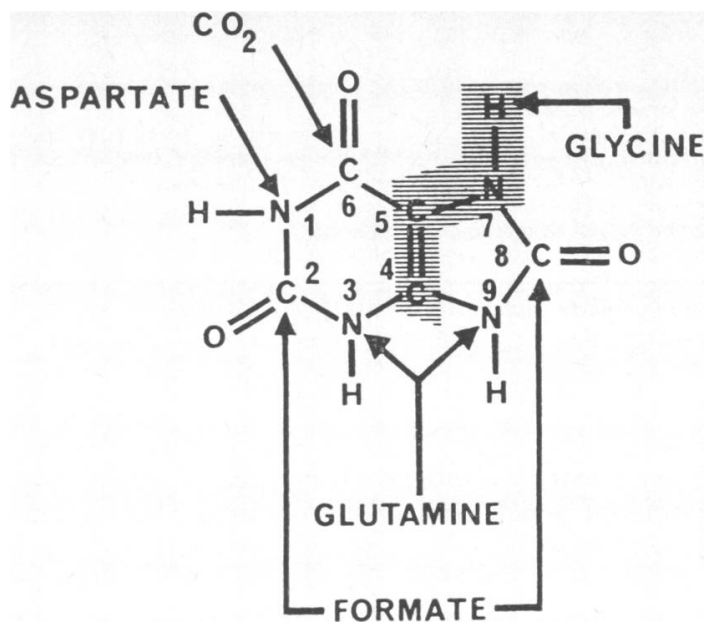

Fig 1 The precursors and numbering of the individual atoms of the uric acid molecule (reproduced from Watts, 1966 and 1972 by permission of the publishers).

hyperuricaemia and hyperuricaciduria in man. Fructose loading does not affect the blood or urine uric acid levels in essential fructosuria due to fructo- kinase (ATP: D-fructose 6-phosphotransferase EC 2.7.1.4) deficiency, whereas marked changes are observed in hereditary fructose intolerance due to phosphofructoaldolase (fructose-1,6-diphosphate $D$ glyceraldehyde-3 phosphate lyase EC 4.1.2.b). Fructose-induced hyperuricaemia may result from several different physiological effects including rapid degradation of adenine nucleotides (Mäenpää, Raivio, and Kekomaki, 1968; Fox and Kelley, 1972). The reduced rate of purine biosynthesis de novo produced by drugs such as allopurinol, orotic acid, and adenine which react with PRPP in vivo are at least partly due to their lowering of the intracellular concentration of the latter compound. Direct evidence suggesting the converse situation in vivo is lacking, except in the case of uric acid overproduction associated with excessive PRPP synthesis, which is discussed below.

The PRPP synthesis is catalysed by PRPPsynthetase (ATP:D-ribose-5-phosphoribosyltransferase EC 2.7.6.1.). Kinetic studies have revealed an ordered bi-bi mechanism for the reaction, the ribose5-phosphate (R5P) binding first followed by binding of $\mathrm{Mg}^{2+}$-ATP, release of AMP and finally release of PRPP. The enzyme shows reversible association and dissociation with estimated molecular weights of

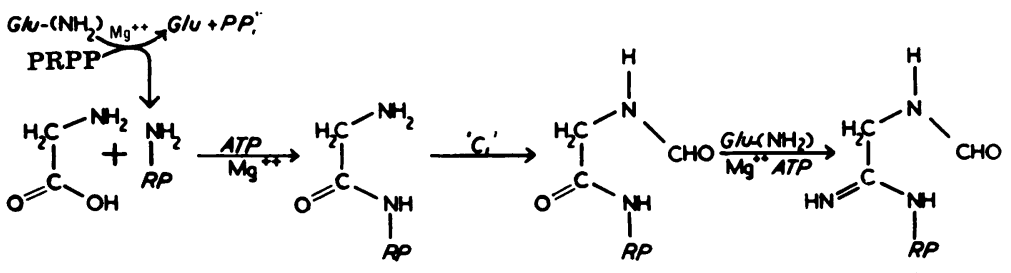

Fig 2 The biosynthesis of inosinic acid (hypoxanthine ribonucleotide). The reaction of glutamine with phosphoribosylpyrophosphate (PRPP) which is the first reaction on the pathway is shown in the top left of the diagram. Glu- $\left(\mathrm{NH}_{2}\right)=$ glutamine. $\mathrm{NH}_{2} \cdot \mathrm{RP}=$ $\beta$-phosphoribosylamine $(P R A) . G l u=$ glutamate . $P P i=$ inorganic pyrophosphate. Asp = aspartate. ' $\mathrm{Cl}$ ' $=$ the active one carbon fragment usually designated formyl (reproduced from Watts, 1966 and 1972 with minor modifications by permission of the publishers).

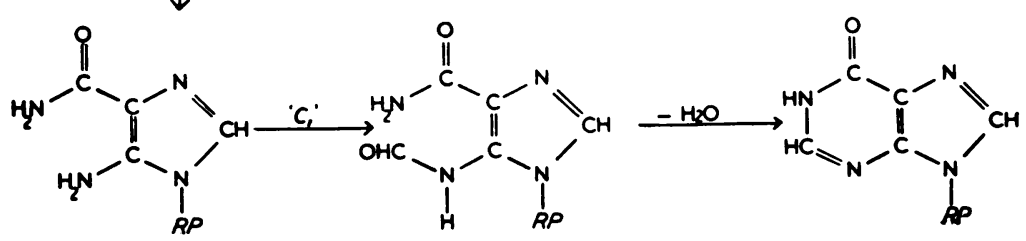




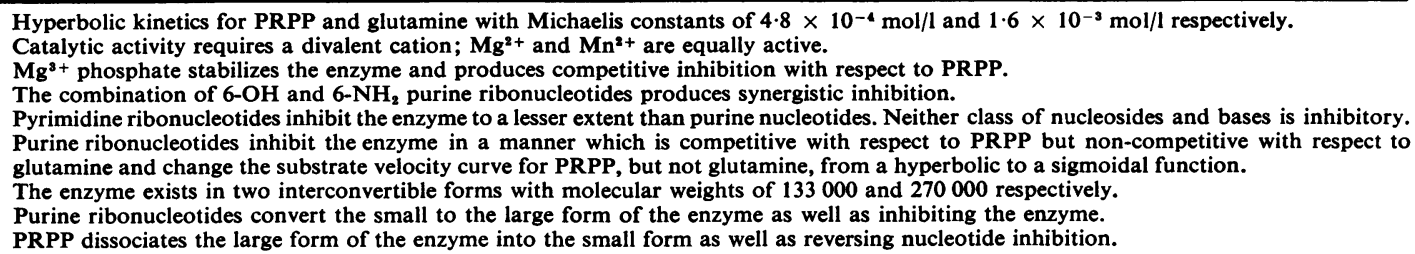

Table 1 The properties of human placental phosphoribosylpyrophosphate amidotransferase [ribosylamine-5'phosphate pyrophosphate phosphoribosyltransferase (glutamate amidating) EC 2.4.2.14] (Holmes, Wyngaarden, and Kelley, 1973)

the native forms of the enzymes varying between 60000 and 1200000 . The aggregated form of the enzyme, which occurs in the presence of $0.3 \mathrm{mmol} / 1$ ATP and $6 \mathrm{mmol} / \mathrm{l} \mathrm{Mg}^{2+}$ appears to be the active and most stable form. The activity of the enzyme is regulated by the following factors: (1) ADP which inhibits competitively with respect to ATP: (2) inhibition by 2,3-diphosphoglycerate (2,3-DPG) and PRPP; (3) non-competitive inhibition by other nucleotides (Fox and Kelley, 1973).

Reem (1972) investigated purine biosynthesis de novo in human spleen cells and in Burkitt lymphoma cells. She found that these tissues not only contained an active phosphoribosylpyrophosphate amidotransferase but that ammonia could replace glutamine and that phosphoribosylamine (PRA) was formed by an alternative pathway directly from R5P and ammonia. The latter reaction was catalyzed by an enzyme which could be separated from phosphoribosylpyrophosphate amidotransferase, and it was also subject to inhibition by the endproducts of the purine synthetic pathway, particularly by AMP and to a lesser extent by GMP. These results agreed with earlier findings in cell-free extracts of leukaemic mouse spleens. They open up the possibility that an alternative mechanism beginning with the reaction of R5P and ammonia may contribute to overall purine biosynthesis de novo, and that the regulation of the rate of purine biosynthesis may be more complex than was formerly thought, depending on the control of two alternative pathways rather than a single rate-limiting reaction for the synthesis of $\beta$-phosphoribosylamine. It should also be noted that R5P is one of the substrates of PRPP synthetase and the formation of $\beta$-phosphoribosylamine from R5P plus ammonia would reduce the substrate availability for PRPP synthesis, increasing further the possibility for the interplay of control mechanisms.

Inosine-5'-phosphate (inosinic acid) is formed from $\beta$-phosphoribosylamine by the sequence of reactions shown in figure 2 . The individual enzymes have been less fully studied in relation to human biochemistry, although they clearly offer other points at which control mechanisms could operate to influence the rate of purine biosynthesis de novo.

PURINE SALVAGE PATHWAYS

Free purine bases of dietary or endogenous origin are converted directly to the corresponding purine- $5^{\prime}$ monophosphate by the purine phosphoribosyltransferase ('pyrophosphorylase') enzymes. These are the so-called purine salvage pathways. Adenine phosphoribosyltransferase or APRT (AMP: pyrophosphate phosphoribosyltransferase EC 2.4.2.7) catalyzes the production of adenosine-5'-phosphate (AMP) from adenine and PRPP. Hypoxanthine guanine phosphoribosyltransferase or HGPRT (IMP: pyrophosphate phosphoribosyltransferase EC 2.4.2.8) catalyzes the formation of guanosine5'-phosphate (GMP) and inosine-5'-phosphate (IMP) from guanine and hypoxanthine respectively. Hypoxanthine guanine phosphoribosyltransferase also converts xanthine to xanthosine- 5 '-phosphate (XMP); this reaction occurs much more slowly than the corresponding reactions with guanine and hypoxanthine. The drugs 6-mercaptopurine, 8-azaguanine, 6-thioguanine, azathioprine, and allopurinol are also converted to their corresponding ribonucleotides by HGPRT. Other specific phosphoribosyltransferases catalyze the reactions of PRPP with orotic acid and nicotinic acid.

Arnold and Kelley (1973) have purified human HGPRT to homogeneity ( 8000 fold) and find that it has a molecular weight of 68000 and is composed of two subunits of equal molecular weight (34000). They also demonstrated three electrophoretically distinct variants which they concluded were due to non-genetic posttranslational alterations of the enzyme protein. Craft, Dean, Watts, and Westwick (1970) investigated some of the kinetic properties of this enzyme and reported results which were compatible with the enzyme having allosteric properties, and hence with its having a regulatory role by virtue of its effect on the supply of IMP and GMP which influence the activity of the rate- 
limiting initial step on the purine biosynthetic pathway de novo. Gutensohn (1973) purified HGPRT from rat brain tissue and found that it resembled the human erythrocyte enzyme closely. Most of the enzyme was present in the soluble fraction of the brain, although the synaptosomes contained a small but significant amount.

The purine salvage pathways are of particular importance in tissues which have a high requirement for purines but low activity with respect to purine synthesis de novo. The bone marrow and brain belong to this category, whereas liver has high activities for both purine synthesis de novo and purine salvage. The quantitative significance of muscles as a source of purine during exercise is not known. The deamination of AMP to IMP is catalyzed by AMP deaminase (AMP: aminohydrolaseEC3.5.4.6.): this reaction occurs during anaerobic muscle contraction and the IMP is further converted to inosine and hypoxanthine. The increased hypoxanthine and xanthine excretion during muscular work was documented by Nasrallah and Al-Khalidi (1964). In addition, although uric acid excretion decreases during severe exertion, there is a net increase in uric acid excretion during the 48-72-hour period after the beginning of which exertion was undertaken (Cathcart, Kennaway, and Leathes, 1908).

Erythrocytes have high purine phosphoribosyltransferase activities and this may be related to their function in respect of purine ribonucleotide transport. The overall biological significance of the purine salvage pathways has been ably reviewed by Murray (1971). Erythrocytes contain active transport systems for both purine bases and nucleosides. It is thought that the purine ribonucleotides which are the product of purine biosynthesis de novo are converted to nucleosides under the influence of the 5 '-nucleotidase (5'-ribonucleotide phosphohydrolase EC 3.1.3.5) attached to the hepatocyte plasma membrane. The nucleoside is further degraded to the free base by nucleoside phosphorylase, and is then converted to ribonucleotide by the erythrocyte phosphoribosyltransferase. It is uncertain if the nucleoside phosphorylase acts before or after the purine enters the red cell. The reverse reactions are also believed to occur in the tissues to which purines are transported.

\section{PURINE RIBONUCLEOTIDE INTERCONVERSION} REACTIONS

Inosinic acid is converted to guanosine- 5 '-phosphate (guanylic acid) and to adenosine-5'-phosphate (adenylic acid) by the ribonucleotide interconversion reactions which are shown together with the purine salvage pathways and the steps which lead to uric acid in figure 3.
Each of these reactions is enzymatically catalyzed, but although they have been well studied, there are relatively few observations which relate specifically to human disease or biochemical pharmacology. Holmes, Pehlke, Leyva, and Kelley (1973) have studied inosinic dehydrogenase (IMP :NAD ${ }^{+}$oxidoreductase EC 1.2.1.14). Assayable amounts of the enzyme were present in human fibroblasts growing in tissue culture, and the enzyme was isolated from human placenta. These authors showed that the activity of the enzyme is regulated by the end products of purine biosynthesis and that it could be another point on the purine biosynthetic pathway at which some drugs and their metabolic products, eg, allopurinol, 6-mercaptopurine, mycophenolic acid, exert their pharmacological effects.

Xanthine oxidase (xanthine oxygen:oxidoreductase EC 1.2.3.2) is of particular clinical interest, its inhibition being the overriding effect when allopurinol is given therapeutically to control hyperuricaemia and hyperuric aciduria. It occurs mainly in liver, milk, and small intestinal mucosa. The molecular weight is about 300000 and it can be dissociated into two subunits of 150000 molecular weight. It contains 2 atoms of molybdenum, 2 flavin adenine dinucleotide (FAD) residues, 8 atoms of non-haem iron, and 8 moles of labile sulphur per molecule. The mechanism of action is complex so that the enzyme itself forms a respiratory chain. The electron flow occurs sequentially from substrate to molybdenum which is reduced from the $\mathrm{Mb}(\mathrm{VI})$ to the $\mathrm{Mb}(\mathrm{V})$ oxidation state, to FAD, to iron and finally to molecular oxygen. The enzyme can function as a dehydrogenase using $\mathrm{NAD}^{+}$as the terminal electron acceptor, a conformational change (from so-called ' $D$ ' to ' $O$ ' form) accompanies the change in receptor specificity and this occurs on storage of the liver enzyme at $-20^{\circ} \mathrm{C}$ (Corté and Stirpe, 1968; 1972). The relative activity of the enzyme as an oxidase or a dehydrogenase varies between different species, and the enzyme itself has a wide substrate specificity which includes aldehydes, pteridines, purine analogues, and purines other than hypoxanthine and xanthine. The two-step oxidation of hypoxanthine involves release of xanthine and rebinding of this second substrate to a possibly different active site.

Human tissues lack uricase (urate: oxygen oxidoreductase EC 1.7.3.3) but one third of the uric acid which is produced in man is destroyed by other uricolytic mechanisms, eg, peroxidatively, or excreted into the gut where it is degraded by bacterial action.

URIC ACID TRANSPORT

The low solubilities of uric acid and its salts are 


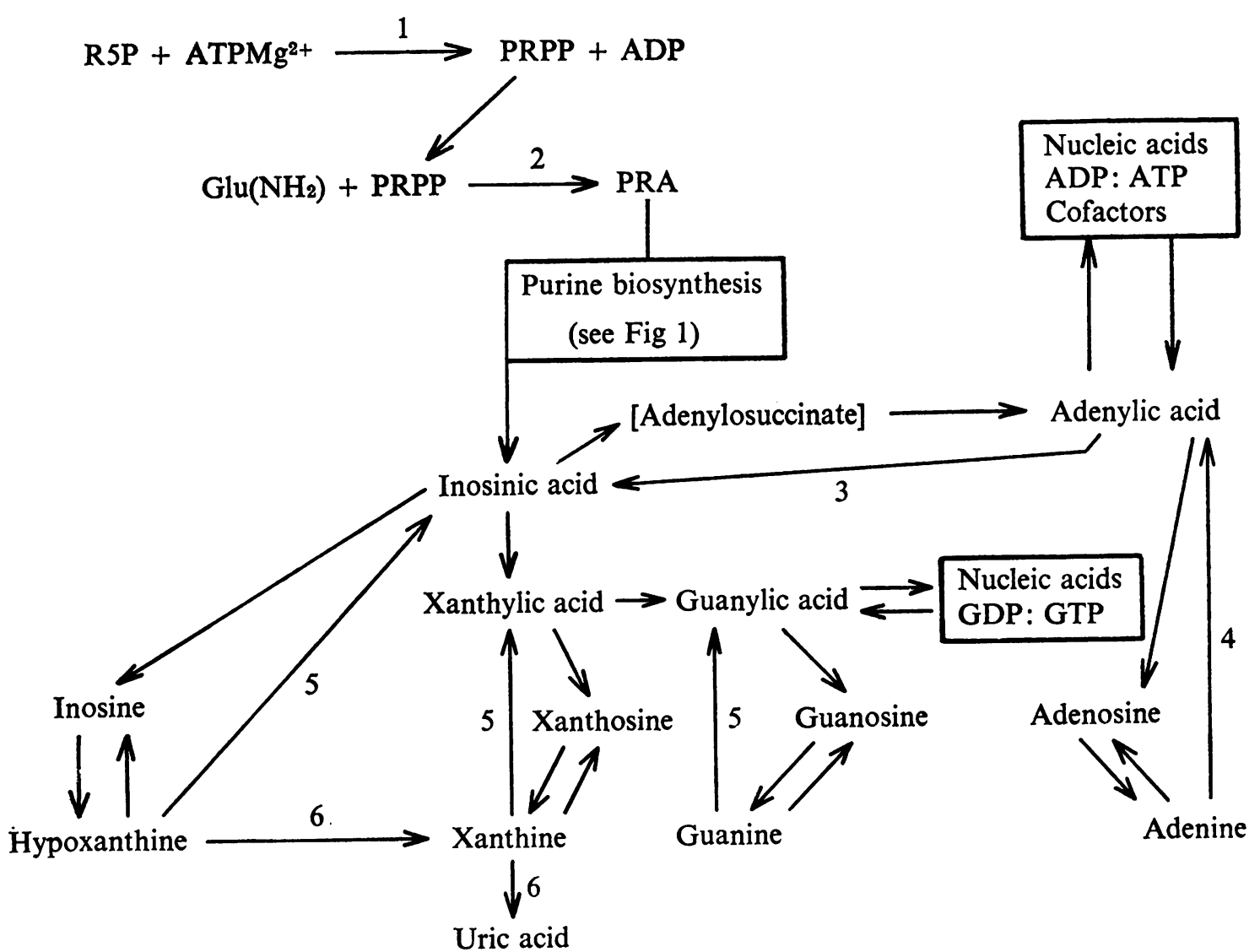

Fig 3 The purine ribonucleotide interconversion reactions and the sites of action of the principal enzymes which are referred to in this paper.

$R S P=$ ribose-5'-phosphate

PRPP = phosphoribosylpyrophosphate

$P R A=\beta$-phosphoribosylamine.

$1=P R P P$-synthetase

$2=$ Glutamine phosphoribosylpyrophosphate amidotransferase.

$3=$ Adenylic acid deaminase

$4=$ Adenine phosphoribosyltransferase (APRT)

$5=$ Hypoxanthine-guanine phosphoribosyltransferase (HGPRT)

$6=$ Xanthine oxidase

The systematic names of the enzymes and their EC numbers are given where they are first mentioned in the text.

responsible for the clinical manifestations of gout. The plasma uric acid is mainly in the form of urate and the solubility is that of monosodium urate, about $7 \mathrm{mg} / 100 \mathrm{ml}$ (theoretical value $=6.4 \mathrm{mg} /$ $100 \mathrm{ml}$ ). Urate binds reversibly to serum albumin as well as to the specific urate binding $\alpha_{1-2}$ globulin, and plasma is readily supersaturated with sodium urate in vitro, and presumably also in vivo, concentrations as high as $90 \mathrm{mg} / 100 \mathrm{ml}$ having been observed during the treatment of myeloproliferative diseases. Drugs such as aspirin and phenylbutazone, and the fatty acids and bilirubin, reduce the plasma protein binding of urate (Klinenberg and Kippen, 1970; Klinenberg, Bluestone, Campion, and Whitehouse, 1973). These workers also report that about $20 \%$ of the serum urate is bound to serum albumin $(5 \mathrm{~g} / 100 \mathrm{ml})$ at free urate concentrations between 1 and $12 \mathrm{mg} / 100 \mathrm{ml}$. High levels of the urate-binding $\alpha_{1-2}$ globulin were reported in some patients with myeloproliferative diseases (Alvsaker, 1966), and inherited low levels of urate binding $\alpha_{1-2}$ globulin are sometimes a factor influencing the occurrence and severity of gout in hyperuricaemic individuals (Alvsaker, 1968; Alvsaker and Seegmiller, 1972). 
RENAL HANDLING OF URIC ACID

The renal handling of urate has been reviewed by Milne (1966) and by Steele (1971). The overall renal clearance is about one tenth of the glomerular filtration rate, ignoring any possible effect of plasma binding. This value is attained by the age of 6 months, the urate clearance being about $35 \%$ of the glomerular filtration rate during the first weeks of life (Passwell, Boichis, Orda, and Brish, 1973). It has been generally accepted that the filtered urate is virtually completely reabsorbed in the more proximal part of the nephron and that the excreted urinary uric acid has been excreted into the distal region of the nephron. However, Diamond and Sharon (1973) have presented evidence for the existence of a postsecretory reabsorptive site for uric acid in man, and that the renal tubular secretion of urate may greatly exceed the uric acid excretion. A wide range of drugs influences the active transport of uric acid across the renal tubular epithelium and this effect can markedly affect the plasma and urinary urate levels. The same drugs produce uricosuria or favour urate retention depending on the dose administered, and the result seen at the clinical level depends on the relationship of the usual therapeutic dose to the uricosuric and urate-retaining doses respectively. Kramp, Lassiter, and Gottschalk (1971), using micropuncture and micro injection techniques, obtained data which were compatible with the operation of a carrier-mediated mechanism for urate reabsorption, and which was probably located at the luminal border of the proximal tubule epithelium.

\section{Gout}

Gout is the syndrome which results from crystallization of monosodium urate from supersaturated body fluids in vivo. This may be due to overproduction or underexcretion of uric acid or to the combination of both of these factors (Seegmiller, Grayzel, Laster, and Liddle, 1961 ; Seegmiller, Grayzel, Howell, and Plato, 1962; Rieselbach, Sorensen, Shelp, and Steele, 1970). The synovial membranes of joints, bursae, and tendon sheaths are favoured sites for the crystallization so that the rheumatological manifestations of the disease dominate the clinical picture. Urinary stones, usually pure uric acid, occur in $10-25 \%$ of gout patients; this is more than 1000 times the incidence in the general population (Gutman and $Y \ddot{u}, 1968$ ). Renal damage by interstitial deposits of monosodium urate occurs, usually mainly in the renal pyramids and produces segmental loss of kidney tissue. Proteinuria and hypertension occur in $10-40 \%$ of gout patients (Gutman and Yü, 1957; Talbott and Terplan, 1960). Sodium urate nephropathy carries a poor prognosis, and, although it can be prevented or arrested by adequate treatment of the gout, the renal damage cannot be reversed. Seegmiller and Frazier (1966) claimed that about $25 \%$ of gout patients died from renal failure; it is of interest that these figures refer to the period before the extensive use of allopurinol, which reduces hyperuricaciduria as well as hypericaemia, and the proportion of patients referred to is roughly the same as the proportion who show excessive purine biosynthesis de novo. The clinical aspects of gout, its treatment, and the clinical investigation of patients with hyperuricaemia have been reviewed in detail by the present writer elsewhere (Watts, 1972). In spite of its frequency, clear-cut biochemical features, and the strong suggestion that polygenic inherited influences are operating, only a disappointingly few cases of gout, asymptomatic hyperuricaemia or hyperuricaciduria with urolithiasis, are associated with an identifiable enzyme defect even when there is uric acid overproduction.

The enzyme abnormalities concerned are: (1) decreased HGPRT activity; (2) increased PRPPsynthetase activity; (3) glucose-6-phosphatase (Dglucose-6-phosphate phosphohydrolase EC 3.1.3.9) deficiency; (4) increased glutathione reductase (NADPH: glutathione oxidoreductase EC 1.6.4.2) activity; (5) increased xanthine oxidase activity.

\section{DECREASED HGPRT ACTIVITY}

The very gross (or 'complete') deficiency of HGPRT associated with the Lesch-Nyhan syndrome (see page 55) is also accompanied by marked uric acid overproduction, multiple uric acid urinary stones, and gout in childhood.

Other mutations of HGPRT are encountered which leave the enzyme with more residual catalytic activity. These patients also present with severe juvenile gout, uric acid urolithiasis but have inconstant and only minor neurological manifestations with mild degrees of mental retardation. The extent to which these cases of incomplete HGPRT deficiency contribute to the gouty population as a whole is uncertain, but it is unlikely to be more than about $1 \%$ of all cases (Delbarre, Cartier, Auscher, de Géry, and Hamet, 1970; Boyle, Greene, and Seegmiller, 1971; Yü, Balis, Krenitsky, Dancis, Silvers, Elion, and Gutman, 1972). Increasing experience has shown that the syndromes of 'complete' HGPRT deficiency (Lesch-Nyhan syndrome) and 'incomplete' HGPRT deficiency form a continuum, and the degree of neurological deficit does not parallel the HGPRT level at least as measured in erythrocytes (Emmerson and Thompson, 1973) this being the tissue on which the enzymological diagnosis must be made. 
INCREASED PRPP-SYNTHETASE ACTIVITY Sperling, Eilam, Persky-Brosh, and De Vries (1972) recognized increased PRPP synthetase activity as a cause of gout in two brothers. These patients show accelerated incorporation of purine bases into purine ribonucleotides in erythrocytes, increased erythrocyte PRPP, and enhanced erythrocyte PRPP generation in vitro with normal HGPRT activity. Hershko, Hershko, and Mager (1968) had previously observed increased purine incorporation into ribonucleotides in some gouty patients. Sperling and his colleagues concluded that the defect in their patients was inherited in an X-linked manner. Further studies revealed that the patient's PRPP synthetase was abnormally resistant to inhibition by orthophosphate, showing increased activity at low orthophosphate concentrations and normal activity at saturating orthophosphate concentrations (Sperling, Persky-Brosh, Boer, and De Vries, 1973). Seegmiller and his colleagues (Becker, Mayer, Wood, and Seegmiller, 1973; Becker, Mayer, and Seegmiller, 1973) have described another pair of sibs in whom uric acid overproduction and gout are associated with increased erythrocyte PRPP synthetase activity; the enzyme abnormality was also demonstrated in fibroblasts from one case. These patients differ from those reported by Sperling et al (1972) because the increased enzyme activity was not related to orthophosphate concentration and the evidence is compatible with a dominant, as opposed to an X-linked, mode of genetic transmission. The observed increase in PRPP synthetase activity may not be the primary enzymological defect but merely reflect decreased activity of another enzyme which alters the concentration of feedback effectors or inducers of PRPP synthetase. An analogous situation exists in acute intermittent porphyria where the increased activity of $\delta$-amino laevulinic acid synthetase was recognized before the primary defect, a partial deficiency of uroporphyrinogen-1 synthetase, was identified (Strand, Felsher, Redeker, and Marver, 1970).

It should be emphasized that only about $25 \%$ of gout patients are overproducers of uric acid, that most of these have normal erythrocyte PRPP levels, and that of the small number in whom the erythrocyte PRPP concentration is increased, some do not have a demonstrably accelerated rate of PRPP synthesis.

\section{GLUCOSE-6-PHOSPHATASE DEFICIENCY}

Type I glycogen storage disease, glucose 6-phosphatase ( $D$-glucose-6-phosphate phosphohydrolase EC 3.1.3.9) deficiency, is associated with hyperuricaemia and gout due to a combination of excessive purine biosynthesis de novo (Alepa, Howell, Klinen- berg, and Seegmiller, 1967; Jakovcic and Sorensen, 1967; Kelley, Rosenbloom, Seegmiller, and Howell, 1968) and urate retention due to the abnormal organic acidaemia which occurs in this disorder (Yü, Sirota, Berger, Halpern, and Gutman, 1957; Goldfinger, Klinenberg, and Seegmiller, 1965). Glucose-6-phosphatase catalyzes the hydrolysis of $D$-glucose-6-phosphate to $D$-glucose and phosphate. It also cleaves inorganic pyrophosphate hydrolytically and catalyzes the formation of $D$-glucose-6phosphate from inorganic pyrophosphate and glucose (Stetten and Taft, 1964). The purine overproduction in type I glycogen storage disease can be explained as follows. Deficiency of glucose-6-phosphatase leaves more glucose-6-phosphate available for metabolism via the phosphogluconate (pentosephosphate) shunt pathway with increased generation of ribose-5-phosphate, the substrate for PRPP synthetase. The increased availability of PRPP favours the disaggregation of phosphoribosylpyrophosphate amidotransferase subunits so that the rate of purine synthesis de novo is increased.

\section{INCREASED GLUTATHIONE REDUCTASE ACTIVITY}

Hyperuricaemia and gout are also associated with the increased glutathione reductase (NADPH: glutathione oxidoreductase EC 1.6.4.2) activity which accompanies the presence of an electrophoretically fast moving variant of this enzyme (Long, 1967). This enzyme variant has a high incidence in negroes and it appears to have an autosomal recessive pattern of inheritance. Increased glutathione reductase activity would increase NADP generation from $\mathrm{NADPH}$, and increased $\mathrm{NADP}+\mathrm{NADPH}$ ratios would increase pentose phosphate shunt activity with generation of ribose-5-phosphate and hence of PRPP by the following sequence of reactions: GSSG + NADPH $\rightarrow$ GSH + NADP +

G-6-P + NADP $+\rightarrow D$-glucono-5-lactone-6phosphate + NADPH

$D$-glucono-5-lactone-6-phosphate $+\mathrm{H}_{2} \mathrm{O} \rightarrow 6$ phospho- $D$-gluconate

6-phospho- $D$-gluconate $+\mathrm{NADP}^{+} \rightarrow D$-ribulose5-phosphate

$D$-ribulose-5-phosphate $\rightarrow D$-ribose-5-phosphate $D$-ribose-5-phosphate + ATP $\rightarrow$ PRPP + AMP The increased availability of PRPP would again increase purine synthesis de novo by its action on phosphoribosylpyrophosphate amidotransferase.

INCREASED XANTHINE OXIDASE ACTIVITY Increased hepatic xanthine oxidase was reported in a group of gout patients by Carcassi, Marcolongo, Marinello, Riario-Sforza, and Boggiano (1969). The incidence of this anomaly and its specific 
relationship to gout remains to be assessed in other patients. Riario-Sforza, Carcassi, Bayeli, Marcolongo, Marinello, and Montagui (1969) did not find similar changes in jejunal mucosa.

THE POSTULATED PRIMARY ABNORMALITY OF PHOSPHORIBOSYLPYROPHOSPHATE

AMIDOTRANSFERASE

The possibility that some cases of uric acid overproduction are due to a primary abnormality of phosphoribosylpyrophosphate amidotransferase which makes it abnormally resistant to feedback inhibition by purine ribonucleotides, or alternatively, in the light of the most recent knowledge, abnormally sensitive to the stimulatory effect of PRPP, has been widely proposed. However, such cases have not yet been identified. The proof of such a metabolic lesion would require inhibitor binding studies, and a detailed investigation of the kinetics and allosteric properties of the purified abnormal enzyme isolated from the patients' tissues. It seems unlikely that such studies will become practicable to any extent at the clinical level.

\section{The Lesch-Nyhan Syndrome}

It was originally proposed that this syndrome was associated with complete deficiency of HGPRT. However, ultrasensitive radiochemical assays have shown that at least some patient's erythrocytes and cultured fibroblasts do contain minute amounts of residual enzyme activity and the catalytically incompetent enzyme protein can be demonstrated electrophoretically and immunochemically (Kelley and Meade, 1970; Bakay and Nyhan, 1971; Arnold, Meade, and Kelley, 1972; Arnold and Kelley, 1973). Molecular heterogeneity between different patients with the syndrome has been demonstrated on the basis of the kinetic properties and heat inactivation curves of the enzyme in blood cells and cultured fibroblasts (McDonald and Kelley, 1971; Kelley and Meade, 1970). The mutant gene is inherited in a sex-linked manner: the affected males do not reproduce, so that one third of the cases are expected to arise from fresh mutations. Experimental evidence for the occurrence of a case as a result of a fresh mutation was presented by McKeran, Andrews, Howell, Gibbs, Chinn, and Watts (1974). It has been widely accepted that lack of HGPRT activity reduces the availability of phosphoribosylpyrophosphate amidotransferase (Seegmiller, Rosenbloom, and Kelley, 1967). The recent study of Holmes, Wyngaarden, and Kelley (1973) emphasizes the importance of the high intracellular PRPP levels which favour dissociation of the rate-limiting phosphoribosylpyrophosphate amidotransferase into its active subunits thereby accelerating purine biosynthesis de novo.

The patients appear normal at birth except for some degree of muscular hypotonia. Choreoathetosis, compulsive self mutilation, aggressiveness, spasticity, and mental retardation gradually become apparent from the age of about 3 months. The athetoid movements affect the trunk musculature as well as the limbs and are associated with athetoid dysarthria and dysphagia. The self mutilation usually takes the form of gnawing at lips and fingers but compulsive head banging on sharp objects and deliberate self injury by burning may occur. The severity of this sympton is much more marked than that which is observed in other retarded children who, although they may show a stereotyped activity which is self damaging, avoid the extensive degree of tissue destruction which patients with the LeschNyhan syndrome may inflict upon themselves. This symptom is not associated with sensory neuropathy, congenital indifference to pain, or dysautonomia. The children appear afraid of their compulsion and are more contented if restrained and wearing gloves so that they cannot bite their hands. Similarly, they may become more amenable and trainable after dental extraction (Watts, McKeran, Brown, Andrews, and Griffiths, 1974). Frustration and excitement make the involuntary movements worse. The prognosis was formerly governed by the development of renal complications, associated with the gross uric acid overproduction, recurrent multiple urinary calculi, urate nephropathy with small, contracted, urate-loaded and fibrotic kidneys, secondary pyelonephritis, renal hypertension, and uraemia. These complications as well as the juvenile tophaceous gout are avoided by giving allopurinol from infancy. Close observation of some of these patients indicates that their degree of mental retardation is less than is at first apparent, their abilities being conditioned by their gross motor dysfunction. Every effort should be made to ensure that these children receive as much education and training as possible by therapists who are experienced with cases of severe athetoid cerebral palsy due to other causes.

The macrocytic anaemia which accompanies the Lesch-Nyhan syndrome can be corrected by giving adenine. This phenomenon, together with the observation that the fibroblasts from these patients grow better in vitro when the culture medium contains added adenine and folate, suggested that these agents, particularly adenine, might improve the neurological manifestations. This has not proved to be so, even when adenine was given from the first week of life (Schulman, Greene, Fujimoto, and Seegmiller, 1971), except in the case reported by 
Demus, Kaiser, and Schaub (1973), who claim some symptomatic improvement. The interpretation of these therapeutic studies is difficult, unless, as in the study of Schulman, Greene, Fujimoto and Seegmiller (1971), the success or failure of therapy can be clearly demarcated. These investigators were able to use the onset of compulsive self mutilation for this purpose. The children show some improvement by virtue of improved general care and attention, and the more stimulating surroundings in which such studies are undertaken. Watts, McKeran, Brown, Andrews, and Griffiths (1974) investigated the effect of enzyme replacement by means of exchange blood transfusion in a 4-year-old patient. The level of circulating HGPRT was increased into the lower part of the normal range and remained above $10 \%$ of the normal value for about 100 days. This value is well within the range encountered in patients with partial HGPRT deficiency who do not show self mutilation, choreoathetosis, or severe retardation. There was no improvement as judged by the overall clinical picture and by the patient's ability to perform a standard task. The latter was judged by cinematographic recordings, which were randomized and scored by a large number of observers who were unfamiliar with the child. These investigators suggest that the study should be repeated beginning exchange transfusion during the neonatal period.

The clinical picture in the less severely affected cases of the Lesch-Nyhan syndrome forms a continuum with that of patients who present with gout or uric acid stones associated with less reduced levels of erythrocyte HGPRT (the so-called 'incomplete' HGPRT deficiency syndrome). Some of these subjects are mildly retarded and have minor neurological abnormalities such as a mild spinocerebellar ataxia. The less severely affected individuals with 'incomplete' HGPRT deficiency syndrome do reproduce so that it has been possible to make the classical test for inheritance of a sexlinked trait, namely, absence of male-to-male inheritance, in these cases (Kelley, Greene, Rosenbloom, Henderson, and Seegmiller, 1969).

The brain damage has been ascribed to the toxic action of the oxypurines, to some other unidentified metabolite, or to failure to conserve purine bases, particularly GMP in the brain. This organ has a low capacity for purine biosynthesis de novo and is heavily dependent on purine salvage pathways. McKeran, Howell, Andrews, Watts, and Arlett (1974) present evidence which suggests that HGPRT deficiency may cause impaired proliferation of brain cells during the perinatal growth spurt and that this is a factor in the development of brain damage. Adams' (1973) observation that the HGPRT activity of rat cerebral cortex increases rapidly during the first three weeks of life, and the similar finding of Gutensohn and Guroff (1972) on whole rat brain support this suggestion. The rate of brain growth in the human neonate is similar to that in the 5-10day-old rat (Davison and Dobbing, 1966) so there may be a similar rapid increase in brain HGPRT activity in the young infant. This would coincide with the period of greatest activity in protein and nucleic acid synthesis and synapse formation. It is therefore of interest that although HGPRT mainly occurs in the soluble fraction of brain tissue, it can also be found in carefully washed synaptosomes (Gutensohn and Guroff, 1972). McKeran, Howell, Andrews, Watts, and Arlett (1974) were unable to distinguish between the effect of lack of GMP and accumulation of toxic metabolite. GMP is important as a constituent of RNA and DNA and as a precursor of GTP. The latter functions as a coenzyme, eg, its reaction with mannose-1-phosphate to yield GDP-mannose as an intermediate for the transfer of mannosyl residues, and its hydrolysis provides energy during the translational stage of protein synthesis.

The brain glycoproteins contain mannose and $\mathrm{N}$-acetyl glucosamine linked to a polypeptide chain through asparagine residues, and the carbohydrate moiety of the molecule is completed by adding mannose, $\mathrm{N}$-acetyl glucosamine, sialic acid, and fucose residues. Interference with either peptide or glycoprotein synthesis during the critical period of brain growth would be expected to produce profound neurological sequelae. However, Nyhan (1973) still favours the toxic factor hypothesis by analogy with the experimental production of selfmutilative gnawing in rats and rabbits given 1,3,7methylpurine or 1,3-methylpurine but not 3,7methylpurine. Although the cerebrospinal fluid levels of hypoxanthine are increased in the Lesch-Nyhan syndrome, higher levels are observed in xanthinuria (congenital xanthine oxidase deficiency) in which there is no neurological dysfunction, and this suggests that at least hypoxanthine is not responsible for the brain damage. Sweetman and Nyhan (1970) report that the patients excrete increased amounts of 5-amino-4-imidazole carboxamide (AIC), AICriboside, hypoxanthine and xanthine, with decreased excretion of adenine and adenosine. These changes presumably reflect the accelerated purine biosynthesis de novo and lack of IMP which is the precursor of AMP via adenylosuccinate (fig 2).

The activity of red cell APRT is increased in the Lesch-Nyhan syndrome. It has been suggested that this is due to stabilization of the enzyme by the abnormally high intracellular concentration of PRPP which protects the enzyme from decrease in activity as the cells become older. 
Fibroblast cultures prepared from the mothers of the affected boys contain two populations of cells, those with HGPRT (HGPRT ${ }^{+}$) and those which lack the enzyme (HGPRT ${ }^{-}$). The numbers of HGPRT $^{+}$and HGPRT ${ }^{-}$cells are not exactly equal as would be predicted by the Lyon hypothesis of random inactivation of the $\mathrm{X}$ chromosome, and this inequality has been explained as being due to metabolic cooperation 1 . The blood cells do not show mosaicism and there is evidence that this is due to impaired growth of HGPRT- blood cell precursors so that the clones of defective cells are bred out and ultimately overgrown by cells derived from the clones of HGPRT ${ }^{+}$cells. This conclusion is based on the study of a family in which the abnormal genes for both HGPRT deficiency and glucose-6phosphate dehydrogenase deficiency were segregating (Nyhan, Bakay, Connor, Marks, and Keele, 1970; Nyhan, 1973), and on studies of the growth of bone marrow progenitor cells from heterozygotes and affected hemizygotes for complete HGPRT deficiency (Lesch-Nyhan syndrome) in tissue culture (McKeran, Andrews, Howell, Gibbs, Chinn, and Watts, 1974). Conversely, other studies have shown the expected mosaicism among the bone marrow cells of a heterozygote for the partial HGPRT deficiency and in her jejunal mucosa (McKeran, Andrews, Howell, Gibbs, Chinn, and Watts, 1974).

Hair follicles display some degree of clonal growth and the property can be used to identify the female carriers of the disorder by virtue of the mosaicism of their hair follicles with respect to the presence of HGPRT in the follicle cells (Gartler, Scott, Goldstein, Campbell, and Sparkes, 1971; Silvers, Cox, Balis, and Dancis, 1972; Francke, Bakay, and Nyhan, 1973; McKeran, Gibbs, and Watts, 1974).

It is possible to establish the genetic status of the fetus of the female carriers of the abnormal gene by studies on cultured amniotic fluid cells, and this has now been of practical value in the management of several women who have previously borne a child with the Lesch-Nyhan syndrome (Fujimoto, SeegMiller, Uhlendorf, and Jacobson, 1968; DeMars, Sarto, Felix, and Benke, 1969; Boyle, Raivio, Astrin, Schulman, Graf, Seegmiller, and Jacobsen, 1970; Watts, 1974b). Affected males show a single population of HGPRT $^{-}$cells, carrier females show HGPRT $^{+}$and HGPRT ${ }^{-}$, and normal males and females show a single population of $\mathrm{HGPRT}^{+}$ cells.

Hamster fibroblasts with mutations at the

${ }^{1}$ Metabolic cooperation is the phenomenon whereby when cultured mammalian cells come into contact their individual metabolism is modified by the exchange of elaborated material (Subak-Sharpe, 1969).
HGPRT locus were used by Subak-Sharpe (1969) in the studies on which he based the concept of metabolic cooperation. Cells which lack HGPRT can grow in the presence of concentrations of azaguanine or 6-mercaptopurine which are lethal to normal cells because they do not convert the drug to its toxic ribonucleotide. The use of selective tissue culture media permits selection for either HGPRT ${ }^{+}$ or HGPRT ${ }^{-}$cells. They can be used to study spontaneous mutation rates, to test the effects of mutagenic compounds on the mutation rate, and for cell hybridization studies. The use of HGPRT- human cells derived from cases of the Lesch-Nyhan syndrome for the study of somatic cell genetics in man is briefly reviewed by Nyhan (1973).

Other Presumably Genetically Determined Conditions with Excessive Purine Biosynthesis

Hooft, van Nevel, and de Schaepdryver (1968) described a girl who clinically resembled cases of the Lesch-Nyhan syndrome, in whom purine biosynthesis de novo was accelerated but who was normouricaemic. Her parents were first cousins. This child clearly suffered from a disorder of purine metabolism which differed from the Lesch-Nyhan syndrome. Unfortunately HGPRT was not measured.

A patient with another apparently inherited disorder of purine metabolism was reported by Nyhan, James, Teberg, Sweetman, and Nelson (1969). This boy failed to thrive and was found to be grossly hyperuricaemic when he was 4 months old. He was mentally retarded and autistic by the age of 3 years. His teeth were dysplastic and he failed to cry with tears. Purine biosynthesis de novo was accelerated, HGPRT was normal, but APRT was increased.

Deficiency of AMP:Pyrophosphate Phosphoribosyltransferase (EC 2.4.2.7) (APRT)

Partial deficiency of this enzyme (activity of erythrocytes between 21 and $37 \%$ of normal) was reported by Kelley, Levy, Rosenbloom, Henderson, and Seegmiller (1968) in four members over three generations of one family. The subjects were all asymptomatic and had no abnormality of purine metabolism, although the propositus also had type III hyper- $\beta$ lipoproteinaemia as a coincidental finding. These authors concluded that the condition was probably due to the operation of a mutant autosomal gene. Fox, Meade, and Kelley (1973) have described a second family with eight affected members over three generations. In this family the propositus also had hyperuricaemia, but the reduced APRT activity 
and the latter trait appeared to segregate independently in the family. The levels of APRT activity in the erythrocytes were similar to those observed in the first family studied, but Fox, Meade, and Kelley (1973) found that the activities of this enzyme in the leucocytes and cultured fibroblasts were normal. They were able to show that the residual APRT activity had normal heat stability and a normal half life in vivo. There was no detectable abnormality in purine metabolism, erythrocyte PRPP and ATP concentrations were normal, the response to an intravenous infusion of fructose (this assesses adenine nucleotide availability in vivo) was normal, and there was a normal response to adenine administration.

\section{Xanthinuria}

The blood and urine uric acid levels are strikingly low in xanthinuria, less than about $1.0 \mathrm{mg} / 100 \mathrm{ml}$ and about $50 \mathrm{mg} / 24$ hours when the patient is taking an unrestricted diet, and the analyses are made by one of the currently routine colorimetric methods. The results of determinations made when the patient is taking a purine-free diet and using a differential spectrophotometric enzymatic method are usually lower, less than $0.5 \mathrm{mg} / 100 \mathrm{ml}$ and $15 \mathrm{mg} / 24$ hours respectively. The cases which had been reported before 1972 were recently summarized by Watts (1972), and although there have been some more recent case reports and family studies (CastroMendoza, Cifuentes Delatte, and Rapado Errazti, 1972; Frayha, Salti, Haidar, Al-Khalidi, and Hemady, 1973; Holmes, Mason, and Kelley, 1973; Auscher, Pasquier, Mercier, and Delbarre, 1973; Wilson and Tapia, 1973), it is improbable that all of the identified cases are reported in the literature now that the syndrome has been well publicized.

The concentrations of hypoxanthine and xanthine in the plasma and urine are increased to about $0.5-0.9 \mathrm{mg} / 100 \mathrm{ml}$ in the case of plasma and to about $100-600 \mathrm{mg} / 24$ hours in the case of urine. These results are expressed as total oxypurines, ie, the sum of hypoxanthine and xanthine; the latter compound accounts for about $60-90 \%$ of the total oxypurines, although the exact proportion is different in individual cases. Low concentrations of oxypurines are sometimes found in normal plasma $(0 \cdot 0-0.25 \mathrm{mg} / 100 \mathrm{ml})$ and hypoxanthine is the main component. Blood samples which are to be analysed for oxypurines should be chilled to $0^{\circ} \mathrm{C}$ immediately they are drawn and centrifuged at $0-4^{\circ} \mathrm{C}$ without delay in order to minimize hypoxanthine leakage from the erythrocytes. The normal urinary excretion of oxypurines is approximately $11-22 \mathrm{mg} / 24$ hours and there is a slight excess of hypoxanthine. The oxypurines are most conveniently determined by differential spectrophotometric enzymatic methods (Chalmers and Watts, 1968; 1969). Holmes, Mason, and Kelley (1973) reported that giving allopurinol to a patient with xanthinuria reduced the ratio xanthine/hypoxanthine in the urine from 6.69 to 0.27 without changing the total purine excretion. Disregarding any possible effect of the drug or its metabolites on the renal tubular handling of the oxypurines, this suggests that there was rather more residual xanthine oxidase catalytic activity with respect to the oxidation of hypoxanthine to xanthine than of xanthine to uric acid.

Most cases of xanthinuria are asymptomatic and the characteristic low uric acid levels are found during investigation for another disease. About one third of the reported cases have presented with xanthine stones, which are radiotranslucent. Two patients have been reported in whom a myopathy was associated with intramuscular hypoxanthine and xanthine crystals (Chalmers, Watts, Pallis, Bitensky, and Chayen, 1969; Chalmers, Watts, Bitensky, and Chayen, 1969). These patients began to experience muscle pain and stiffness when they were about 30 years old (Chalmers, Johnson, Pallis, and Watts, 1969). The increased concentrations of hypoxanthine and xanthine in the muscle biopsies was also demonstrated by means of an integrated ion current technique with the high resolution mass spectrometer. Only a few milligrams of dessicated tissue were needed for these measurements (Parker, Snedden, and Watts, 1969; 1970).

The results of family studies are compatible with the affected individuals being homozygous for a rare autosomal recessive mutant gene. Some of the presumably heterozygous individuals excreteamounts of oxypurines which are intermediate between the normal range and the amounts excreted by patients with xanthinuria. Their blood or urine uric acid levels are normal. Other presumably heterozygous subjects excrete normal amounts of oxypurines as well as uric acid. The reported cases of xanthine urolithiasis with normal urinary excretion of uric acid which date from the period before congenital xanthine oxidase deficiency (xanthinuria) was recognized may have been the heterozygous carriers.

The metabolic lesion has been demonstrated in liver tissue, jejunal mucosa, and in colostrum, and prevents the oxidation of both hypoxanthine and xanthine. The drug allopurinol [4-hydroxypyrazolo (3,4-d)pyrimidine] is a structural isomer of hypoxanthine, and is oxidized to the xanthine isomer oxipurinol [4,6-dihydroxypyrazolo (3,4-d)pyrimidine]. Chalmers, Parker, Simmonds, Snedden, and Watts (1969) reported the excretion of oxi- 
purinol by a patient with xanthine oxidase deficiency who was taking allopurinol. Ausher, Pasquier, Mercier, and Delbarre (1973) have confirmed this observation and reported the analogous oxidation of 4-thio-pyrazolo-pyrimidine (thiopurinol), the rate of excretion of the oxidation products being the same in xanthinuric and non-xanthinuric subjects. It seems likely that this represents oxidation of the drug by aldehyde oxidase (aldehyde:oxygen oxidoreductase EC 1.2.3.1) (Johns, Spector, and Robins, 1969) rather than metabolism of allopurinol via oxidation of its ribonucleotide analogue, as originally suggested by Chalmers, Parker, Simmonds, Snedden, and Watts (1969). Aldehyde oxidase is an iron, molybdenum and coenzyme- $\mathrm{Q}_{10}$, containing flavoprotein (Rajagopolan, Fridovich, and Handler, 1962), which is distinct from xanthine oxidase with which it has sometimes been confused. Elion, Kovensky, Hitchings, Metz, and Rundles (1966) found that a xanthinuric patient did not excrete oxipurinol when given allopurinol. The validity of this observation was questioned by later workers (Chalmers et al, 1969) on the grounds that the drug had not been given for a sufficiently long period for this effect to have become manifest. However, Holmes, Mason, and Kelley (1973) have recently reported another patient in whom allopurinol was apparently not oxidized to oxipurinol. Further work is needed to establish the cause of this apparent heterogeneity in the disorder, with particular attention being paid to the level of residual activity for the oxidation of hypoxanthine to xanthine, the activity of aldehyde oxidase, and the pharmacodynamics of allopurinol in these patients.

The renal clearance of the oxypurines (hypoxanthine plus xanthine) is increased to about $80 \%$ of the glomerular filtration rate in xanthinuria due to the increased filtered load of oxypurines (Goldfinger, Klinenberg, and Seegmiller, 1965). Hypoxanthine and xanthine are cleared by the kidneys at about the same rate and appear to be both reabsorbed and secreted by the renal tubules (Chalmers, Johnson, Pallis, and Watts, 1969).

Allopurinol and its oxidation product oxipurinol inhibit xanthine oxidase powerfully in vivo, producing iatrogenic xanthinuria. The use of allopurinol in the treatment of gout has not been associated with xanthine stone formation although this complication has occurred in children with the LeschNyhan syndrome who were taking the drug (Seegmiller, 1968; Greene, Fujimoto, and Seegmiller, 1969). The early fears that xanthine oxidase inhibition by allopurinol might interfere with the transport and mobilization of iron have not been substantiated.

Patients with xanthinuria require no specific treatment unless stone formation occurs when a high fluid intake and alkalinization of the urine are indicated.

\section{Xeroderma Pigmentosum}

The association of abnormal cutaneous photosensitivity with microcephaly, mental retardation, and hypogonadism forms a striking clinical syndrome with an autosomal recessive pattern of inheritance. The skin manifestations usually appear in infancy or childhood; they progress from erythema, through a stage of multiple pigmented hypertrophic warty lesions with scarred atrophic telangiectatic areas, to the development of multiple skin cancers. Initially, tear production is excessive but later the eyes are damaged by scarring of the eyelids, conjunctivae, and corneae. In addition to mental subnormality, some patients are spastic or have cerebellar and sensorimotor ataxia.

These patients are abnormally sensitive to light of wavelength $280-310 \mathrm{~nm}$, and fibroblasts cultured from skin biopsies show absent or greatly reduced capacity to repair ultraviolet radiation induced DNA damage. This is attributed to deficiency of the endonuclease which normally initiates DNA repair (Cleaver, 1971). The biochemical abnormality can now be positively identified during life (Epstein, Fukuyama, and Epstein, 1969) and in the fetus before birth (Regan, Setlow, Kaback, Howell, Klein, and Burgess, 1971). This should facilitate the clinical differentiation from the dominantly inherited 'basal cell naevus' syndrome (Binkley and Johnson, 1951) in which the naevi are associated with dental cysts, skeletal abnormalities, and sometimes mental retardation, and from Bloom's syndrome (photosensitivity, skin malignancies, and increased chromosome breaks) (German, 1969).

There have been no studies to assess the effect of this metabolic lesion on the rate of purine biosynthesis or the dynamics of uric acid metabolism, although widespread hyperplastic skin lesions in psoriasis are associated with secondary changes in these parameters (Eisen and Seegmiller, 1961).

\section{Defects in the Renal Handling of Uric Acid}

Reduced uric acid excretion in the presence of a normal rate of uric acid production appears to underlie some cases of essential hyperuricaemia and gout. Glomerular function is not demonstrably altered so this presumably relates to an imbalance between renal tubular reabsorption and secretion, although its molecular basis has not been defined. Hyperuricaemia occurs in a diversity of disorders where, in the absence of increased uric acid biosynthesis de novo (urate overproduction) or a glomeruler lesion it is 
ascribed to the effect of the primary pathological process on the renal tubular transport mechanisms for urate. Primary hyperparathyroidism (Scott, Dixon, and Bywaters, 1964) and essential hypertension (Breckenridge, 1966) are examples of such disorders.

A renal tubular net reabsorption defect with hypouricaemia occurs in association with other manifestations of renal tubule transport disorders in the Fanconi syndrome. Some cases of this syndrome are due to recognized inborn errors of metabolism: cystinosis, hereditary tyrosinaemia, Wilson's disease, galactosaemia, hereditary fructose intolerance. It is also associated with Lowe's syndrome. Renal damage by toxic substances also accounts for another group of cases of the Fanconi syndrome, for example, cadmium, lysol, and degraded tetracycline. However, a proportion of these cases still lack an aetiological explanation.

An apparently isolated renal tubule reabsorption defect with hypouricaemia was reported in an apparently healthy young man by Praetorius and Kirk (1950). Plasma uric acid values were in the range $0 \cdot 2-0 \cdot 6 \mathrm{mg} / 100 \mathrm{ml}$ with urinary excretion of about $700 \mathrm{mg} / 24$ hours. Uric acid clearances ranged from 162 to $284 \mathrm{ml} / \mathrm{min}$ (normal $=7$ to $10 \mathrm{ml} / \mathrm{min}$ ). The original report of increased plasma oxypurine levels in this case appears to have been due to breakdown of erythrocyte ribonucleotides before the plasma was separated from the erythrocytes. Simkin, Skeith, and Healey (1973) have reported another similar case and do not mention any changes in oxypurine levels. They showed that pyrazinamide, salicylate, and probenecid all inhibited the urate secretion, and they concluded that the biphasic effect of uricosuric drugs in normal subjects must result from independent and antagonistic action on separate secretory and reabsorptive systems.

\section{Conclusions}

The clinical and biochemical effects of identified molecular variants of the enzymes which catalyze purine biosynthesis, salvage, and degradation and excretion have been described as far as they are known. Purine biosynthesis, salvage and degradation are geared to maintaining the supply of purine nucleotides for: (1) DNA and RNA biosynthesis; (2) the production of the high energy triphosphates; (3) for certain coenzymes. It seems reasonable to suggest that other metabolic lesions will be identified in this area of metabolism, particularly if alternative metabolic pathways are possible so that the mutation would not be lethal, or if they are of a type which acts by altering the concentration or availability of a regulatory substrate. Mutations involving the polymerization of nucleotides to form DNA and RNA would presumably be incompatible with any embryonic development. However, it is of interest that a mutation of the endonuclease responsible for the repair of DNA is recognizable in association with a disease entity characterized by malignant disease which can be associated with a specific cause of damage to nuclear material. The extent to which genetic factors participate in the multifactorial aetiology of malignant disease in general remains a problem for future study.

\section{References}

Adams, A. (1973). The development, distribution and properties of purine phosphoribosyltransferase in mammals. Ph.D. Thesis. University of Edinburgh.

Alepa, F. P., Howell, R. R., Klinenberg, J. R., and Seegmiller, J. E. (1967). Relationships between glycogen storage disease and tophaceous gout. Amer. J. Med., 42, 58-66.

Alvsaker, J. O. (1966). Uric acid in human plasma. VI. Isolation and identification of plasma proteins interacting with urate. Scand. J. clin. lab. Invest., 18, 227-239.

Alvsaker, J. O. (1968). Genetic studies in primary gout: investigations on the plasma levels of the urate-binding $\alpha_{1-2}$-globulin in individuals from two gouty kindreds. J. clin. Invest., 47, 1254-1261.

Alvsaker, J. O., and Seegmiller, J. E. (1972). Plasma concentrations of the urate-binding alpha $a_{1-2}$-globulin in patients with different types of primary gout as compared to healthy control subjects. Europ. J. clin. Invest., 2, 66-71.

Arnold, W. J., and Kelley, W. N. (1973). Human hypoxanthineguanine phosphoribosyltransferase: purification and properties. (Abstr.) Israel J. med. Sci., 9, 1082.

Arnold, W. J., Meade, J. C., and Kelley, W. N.,(1972). Hypoxanthineguanine phosphoribosyltransferase: characteristics of the mutant enzyme in erythrocytes from patients with the LeschNyhan syndrome. J. clin. Invest., 51, 1805-1812.

Auscher, C., Pasquier, C., Mercier, N., and Delbarre, F. (1973). Oxidation of pyrazolo [3,4- $d$ ] pyrimidine in a xanthinuric man. (Abstr.) Israel J. med. Sci., 9, 1082-1083.

Bakay, B., and Nyhan, W. L. (1971). The separation of adenine and hypoxanthine-guanine phosphoribosyl transferase isoenzymes by disc gel electrophoresis. Biochem. Genet., 5, 81-90.

Becker, M. A., Mayer, L. J., and Seegmiller, J. E. (1973). Gout with purine overproduction due to increased phosphoribosylpyrophosphate synthetase activity. Amer. J. Med., 55, 232-242.

Becker, M. A., Mayer, L. J., Wood, A. W., and Seegmiller, J. E. (1973). Purine overproduction in man associated with increased phosphoribosylpyrophosphate synthetase activity. Science, 179, 1123-1126.

Boyle, J. A., Greene, M. L., and Seegmiller, J. E. (1971). Alterations in the activity of hypoxanthine and adenine phosphoribosyltransferase in patients with hyperuricaemia and gout. Quart. J. Med., N.S., 40, 574-575.

Boyle, J. A., Raivio, K. O., Astrin, K. H., Schulman, J. D., Graf M. L., Seegmiller, J. E., and Jacobsen, C. B. (1970). LeschNyhan syndrome-preventive control by prenatal diagnosis. Science, 169, 688-689.

Boyle, J. A., Raivio, K. O., Becker, M. A., and Seegmiller, J. E. (1972). Effects of nicotinic acid on human fibroblast purine biosynthesis. Biochim. biophys. Acta (Amst.), 269, 179-183.

Breckenridge, A. (1966). Hypertension and hyperuricaemia. Proc. roy. Soc. Med., 59, 316-319.

Binkley, G. W., and Johnson, H. H. Jr. (1951). Epithelioma adenoides cysticum: basal cell nevi, agenesis of the corpus callosum and dental cysts. Arch. Derm., 63, 73-84.

Carcassi, A., Marcolongo, R., Jr., Marinello, E., Rairio-Sforza, G., and Boggiano, C. (1969). Liver xanthine oxidase in gouty patients. Arth. and Rheum., 12, 17-20.

Caskey, C. T., Ashton, D. M., and Wyngaarden, J. B. (1964). The enzymology of feedback inhibition of glutamine phosphoribosylpyrophosphate amidotransferase by purine ribonucleotides. J. biol. Chem., 239, 2570-2579. 
Castro-Mendoza, H. J., Cifuentes Delatte, L., and Rapado Errazti, A. (1972). Una neuva observacion de xantinuria familiar. Rev. clin. esp., 124, 341-352.

Cathcart, E. P., Kennaway, E. L., and Leathes, J. B. (1908). On the origin of endogenous uric acid. Quart. J. Med., 1, 416-447.

Chalmers, R. A., Johnson, M., Pallis, C., and Watts, R. W. E. (1969). Xanthinuria with myopathy (with some observations on the renal handling of oxypurines in the disease). Quart. J. Med., 38, 493-512.

Chalmers, R. A., Parker, R., Simmonds, H. A., Snedden, W., and Watts, R. W. E. (1969). Conversion of 4-hydroxypyrazolo $[3,4-d]$ pyrimidine (allopurinol) into 4,6-dihydroxypyrazolo [3,4-d]pyrimidine (oxipurinol) in vivo in the absence of xanthine-oxygen oxidoreductase. Biochem. J., 112, 527-532.

Chalmers, R. A., and Watts, R. W. E. (1968). An enzymatic spectrometric method for the determination of 'oxypurines' (hypoxanthine plus xanthine) in urine and blood plasma. Analyst, 93, 354-362.

Chalmers, R. A., and Watts, R. W. E. (1969). The separate determination of xanthine and hypoxanthine in urine and blood plasma by an enzymatic differential spectrophotometric method. Analyst, 94, 226-233.

Chalmers, R. A., Watts, R. W. E., Bitensky, L., and Chayen, J. (1969). Microscopic studies on crystals in skeletal muscle from two cases of xanthinuria. J. Path., 99, 45-56.

Chalmers, R. A., Watts, R. W. E., Pallis, C., Bitensky, L., and Chayen, J. (1969). Crystalline deposits in striped muscle in xanthinuria. Nature (Lond.), 221, 170-171.

Cleaver, J. E. (1969). Xeroderma pigmentosum: a human disease in which an initial stage of DNA repair is defective. Proc. nat. Acad. Sci. (Wash.), 63, 428-435.

Corte, E. della, and Stirpe, F. (1968). Regulation of zanthine oxidase in liver: modifications of the enzyme activity of rat liver supernatant on storage at $-20^{\circ}$. Biochem. $J ., 108,349-351$.

Corte, E. della, and Stirpe, F. (1972). The regulation of rat liver xanthine oxidase: involvement of thiol groups in the conversion of the enzyme activity from dehydrogenase (Type D) into oxidase (Type $\mathrm{O}$ ) and purification of the enzyme. Biochem. J., 126, 739-745.

Craft, J. A., Dean, B. M., Watts, R. W. E., and Westwick, W. J. (1970). Studies on human erythrocyte IMP: pyrophosphate phosphoribosyltransferase. Europ. J. Biochem., 15, 367-373.

Davison, A. N., and Dobbing, J. (1966). Myelination as a vulnerable period in brain development. Brit. med. Bull., 22, 40-44.

Delbarre, F., Cartier, P., Auscher, C., de Géry, A., and Hamet, M. (1970). Dyspurinies par déficit en hypoxanthine-guaninephosphoribosyl-transferase fréquence et caractères cliniques de l'anenzymose. Presse med., 78, 729-734.

DeMars, R., Sarto, G., Felix, J. S., and Benke, P. (1969). LeschNyhan mutation: prenatal detection with amniotic fluid cells. Science, 164, 1303-1305.

Demus, A., Kaiser, W., and Schaub, J. (1973). The Lesch-Nyhan syndrome. Metabolic studies during administration of adenine. Z. Kinderheilk, 114, 119-130.

Diamond, H., and Sharon, E. (1973). Evidence for a postsecretory reabsorptive site for uric acid in man. (Abstr.) Israel J. med. Sci., 9, 1088-1089.

Eisen, A. Z., and Seegmiller, J. E. (1961). Uric acid metabolism in psoriasis. J. clin. Invest., 40, 1486-1494.

Elion, G. B., Kovensky, A., Hitchings, G. H., Metz, E., and Rundles, R. W. (1966). Metabolic studies of allopurinol, an inhibitor of xanthine oxidase. Biochem. Pharmacol., 15, 863-880.

Emmerson, B. T., and Thompson, L. (1973). The spectrum of hypoxanthineguanine phosphoribosyltransferase deficiency. Quart. J. Med., 42, 423-440.

Epstein, W. L., Fukuyama, K., and Epstein, J. H. (1969). Early effects of ultraviolet light on DNA synthesis in human skin in vivo. Arch. Derm., 100, 84-89.

Fox, I. H., and Kelley, W. N. (1972). Studies on the mechanism of fr' 'ctose-induced hyperuricaemia in man. Metabolism, 21, 713-721.

Fox, I. H., and Kelley, W. N. (1973). Human phosphoribosylpyrophosphate synthetase: properties and regulation. (Abstr.) Israel J. med. Sci., 9, 1094.

Fox, I. H., Meade, J. C., and Kelley, W. N. (1973). Adenine phosphoribosvitransferase deficiency in man. Report of a second family. Amer. J. Med., 55, 614-620.
Fox, I. H., Wyngaarden, J. B., and Kelley, W. N. (1970). Depletion of erythrocyte phosphoribosylpyrophosphate in man. A newly observed effect of allopurinol. New Engl. J. Med., 283, 1177-1182.

Francke, U., Bakay, B., and Nyhan, W. L. (1973). Detection of heterozygous carriers of the Lesch-Nyhan syndrome by electrophoresis of hair root lysates. J. Pediat., 82, 472-478.

Frayha, R. A., Salti, I. S., Haidar, G. I. A., Al-Khalidi, U., and Hemady, K. (1973). Hereditary xanthinuria and xanthine urolithiasis an additional 3 cases. J. Urol., 109, 871-873.

Fujimoto, W. Y., Seegmiller, J. E., Uhlendorf, B. W., and Jacobson, C. B. (1968). Biochemical diagnosis of an $\mathrm{X}$-linked disease in utero. Lancet, 2, 511-512.

Gartler, S. M., Scott, R. C., Goldstein, J. L., Campbell, B., and Sparkes, R. (1971). Lesch-Nyhan syndrome: rapid detection of heterozygotes by use of hair follicles. Science, 172, 572-574.

German, J. (1969). Bloom's syndrome. I. Genetical and clinical observations in the firsi twenty-seven patients. Amer. $J$. hum. Genet., 21, 196-227.

Goldfinger, S., Klinenberg, J. R., and Seegmiller, J. E. (1965). The renal excretion of oxypurines. J. clin. Invest., 44, 623-628.

Greene, M. L., Fujimoto, W. Y., and Seegmiller, J. E. (1969). Urinary xanthine stones-a rare complication of allopurinol therapy. New Engl. J. Med., 280, 426-427.

Greene, M. L., and Seegmiller, J. E. (1969). Erythrocyte 5-phosphoribosyl-1-pyrophosphate (PRPP) in gout: importance of PRPP in the regulation of human purine synthesis. Arth. and Rheum., 12, 666-667.

Gutensohn, W. (1973). Purification and characterisation of a neural hypoxanthine-guanine phosphoribosyltransferase. (Abstr.) Israel J. med. Sci., 9, 1097.

Gutensohn, W., and Guroff, G. (1972). Hypoxanthine-guaninephosphoribosyltransferase from rat brain (purification kinetic properties, development and distribution). J. Neurochem., 19, 2139-2150.

Gutman, A. B., and Yü, T. F. (1957). Renal function in gout: with a commentary on the renal regulation of urate excretion, and the role of the kidney in the pathogenesis of gout. Amer. J. Med., 23, 600-622.

Gutman, A. B., and Yü, T. F. (1968). Uric acid nephrolithiasis. Amer. J. Med., 45, 756-779.

Henderson, J. F., and Khoo, M. K. Y. (1965). Synthesis of 5-phosphoribosyl 1-pyrophosphate from ribonucleosides in Ehrlich ascites tumor cells in vitro. J. biol. Chem., 240, 2363-2366.

Hershko, A., Hershko, C., and Mager, J. (1968). Increased formation of 5-phosphoribosyl-1-pyrophosphate in red blood cells of some gouty patients. Israel J. med. Sci., 4, 939-944.

Holmes, E. W., Mason, D. H., Jr., and Kelley, W. N. (1973). Xanthine oxidase deficiency: studies in a previously unreported case. (Abstr.) Israel J. med. Sci., 9, 1100.

Holmes, E. W., McDonald, J. A., McCord, J. M., Wyngaarden, J. B., and Kelley, W. N. (1973). Human glutamine phosphoribosylpyrophosphate amidotransferase: kinetic and regulatory properties. J. biol. Chem., 248, 144-150.

Holmes, E. W., Pehlke, M. D., Leyva, A., and Kelley, W. N. (1973). Human inosinic acid dehydrogenase: regulatory properties in vitro and in vivo. Israel J. med. Sci., 9, 21-22.

Holmes, E. W., Wyngaarden, J. B., and Kelley, W. N. (1973). Human glutamine phosphoribosylpyrophosphate amidotransferase: kinetics, regulation and conformational changes. Israel $J$. med. Sci., 9, 21.

Hooft, C., van Nevel, C., and de Schaepdryver, A. F. (1968) Hyperuricosuric encephalopathy without hyperuricaemia. Arch. dis. Child., 43, 734-737.

Jakovcic, S., and Sorenson, L. B. (1967). Studies of uric acid and metabolism in glycogen storage disease associated with gouty arthritis. Arth. and Rheum., 10, 129-134.

Johns, D. G., Specktor, T., and Robins, R. K. (1969). Studies on the mode of oxidation of pyrazolo $(3,4-d)$ pyrimidine by aldehyde oxidase and xanthine oxidase. Biochem. Pharmacol., 18, 2371-2383.

Kelley, W. N., Fox, I. H., and Wyngaarden, J. B. (1970). Regulation of purine biosynthesis in cultured human cells. I. Effects of orotic acid. Biochim. Biophys. Acta (Amst.), 215, 512-516.

Kelley, W. N., Greene, M. L., Rosenbloom, F. M., Henderson, J. F., and Seegmiller, J. E. (1969). Hypoxanthine-guanine phosphoribosyltransferase deficiency in gout. Ann. int. Med., 70, 155-206.

Kelley, W. N., Levy, R. I., Rosenbloom, F. M., Henderson, J. F. and Seegmiller, J. E. (1968). Adenine phosphoribosyltransferase 
deficiency: a previously undescribed genetic defect in man. J. clin. Invest., 47, 2281-2289.

Kelley, W. N., and Meade, J. C. (1970). Studies on hypoxanthineguanine phosphoribosyltransferase in fibroblasts from patients with the Lesch-Nyhan syndrome. Evidence for genetic heterogeneity. J. biol. Chem., 246, 2953-2958.

Kelley, W. N., Rosenbloom, F. M., Seegmiller, J. E., and Howell, R. R. (1968). Excessive production of uric acid in type glycogen storage disease. J. Pediat., 72, 488-496.

Klinenberg, J. R., Bluestone, R., Campion, D., and Whitehouse, M. (1973). Binding of urate to plasma proteins. (Abstr.) Israel J. med. Sci., 9, 1103.

Klinenberg, J. R., and Kippen, I. (1970). The binding of urate to plasma proteins determined by means of equilibrium dialysis. J. lab. clin. Med., 75, 503-510.

Kramp, R. A., Lassiter, W. E., and Gottschalk, C. W. (1971). Urate-2-14 $\mathrm{C}$ transport in the rat nephron. J. clin. Invest., 50, 35-48.

Long, W. K. (1967). Glutathione reductase in red blood cells: variant associated with gout. Science, 155, 712-713.

Mäenpää, P. H., Raivio, K. O., and Kekomaki, M. P. (1968). Liver adenine nucleotides: fructose-induced depletion and its effect on protein synthesis. Science, 161, 1253-1254.

McDonald, J. A., and Kelley, W. N. (1971). Lesch-Nyhan syndrome: altered kinetic properties of mutant enzyme. Science, 171, 689-691.

McKeran, R. O., Andrews, T. M., Howell, A., Gibbs, D. A., Chinn, S., and Watts, R. W. E. (1974). The diagnosis of the carrier state for the Lesch-Nyhan syndrome. Quart. J. Med., in press.

McKeran, R. O., Gibbs, D. A., and Watts, R. W. E. (1974). Some aspects of the use of hair follicles for the biochemical study of inborn errors of metabolism. In Proceedings of the 11th Annual Meeting of the Society for the Study of Inborn Errors of Metabol$i s m$, edited by J. T. Ireland and J. Holton. Churchill Livingstone: Edinburgh \& London.

McKeran, R. O., Howell, A., Andrews, T. M., Watts, R. W. E., and Arlett, C. F. (1974). Observations on the growth in vitro of myeloid progenitor cells and fibroblasts from hemizygotes and heterozygotes for 'complete' and 'partial' hypoxanthineguanine phosphoribosyltransferase (HGPRT) deficiency, and their relevance to the pathogenesis of brain damage in the Lesch-Nyhan syndrome. J. Neurol. Sci., 22, 183-195.

Milne, M. D. (1966). Urate excretion. Proc. roy. Soc. Med., 59, 308-310.

Murray, A. W. (1971). The biological significance of purine salvage. Ann. Rev. Biochem., 40, 811-826.

Nasrallah, S., and Al-Khalidi, U. (1964). Nature of purines excreted in urine during muscular exercise. J. appl. Physiol., 19, 246-248.

Nyhan, W. L. (1973). The Lesch-Nyhan syndrome. Ann. Rev. Med., 24, 41-60.

Nyhan, W. L., Bakay, B., Connor, J. D., Marks, J. F., and Keele, D. K. (1970). Hemizygous expression of glucose-6-phosphate dehydrogenase in erythrocytes of heterozygotes for the Lesch-Nyhan syndrome. Proc. nat. Acad. Sci. (Wash.), 65, 214-218.

Nyhan, W. L., James, J. A., Teberg, A. J., Sweetman, L., and Nelson, L. G. (1969). A new disorder of purine metabolism with behavioral manifestations. J. Pediat., 74, 20-27.

Parker, R., Snedden, W., and Watts, R. W. E. (1969). The mass-spectrometric identification of hypoxanthine and xanthine ('oxypurines') in skeletal muscle from two patients with congenital xanthine oxidase deficiency (xanthinuria). Biochem. J., 115, 103-108.

Parker, R., Snedden, W., and Watts, R. W. E. (1970). The quantitative determination of hypoxanthine and xanthine ('oxypurines') in skeletal muscle from two patients with congenital xanthine oxidase deficiency (xanthinuria). Biochem. J., 116, 317-318.

Passwell, J., Boichis, H., Orda, S., and Brish, M. (1973). Uric acid excretion in infants. (Abstr.) Israel J. med. Sci., 9, 1108.

Praetorius, E., and Kirk, J. E. (1950). Hypouricemia: with evidence for tubular elimination of uric acid. J. lab. clin. Med., 35, $865-868$.

Rajagopolan, K. V., Fridovich, I., and Handler, P. (1962). Hepatic aldehyde oxidase. I. Purification and properties. J. biol. Chem., 237, 922-928.

Reem, G. H. (1972). De novo purine biosynthesis by two pathways in Burkitt lymphoma cells and in human spleen. J. clin. Invest., 51, 1058-1062.

Regan, J. D., Setlow, R. B., Kaback, M. M., Howell, R. R., Klein, E., and Burgess, G. (1971). Xeroderma pigmentosum: a rapid sensitive method for prenatal diagnosis. Science, 174, 147-150.

Riario-Sforza, G., Carcassi, A., Bayeli, P. F., Marcolongo, R. Marriello, E., and Montagnani, M. (1969). Attività xantinaossidasica bella mucosa cliguinale di soggetti gottosi. Boll. soc. ital. Biol., sper., 45, 785-786.

Rieselbach, R. E., Sorensen, L. B., Shelp, W. D., and Steele, T. H. (1970). Diminished renal urate secretion per nephron as a basis for primary gout. Ann. intern. Med., 73, 359-366.

Rowe, P. B., Coleman, M. D., and Wyngaarden, J. B. (1970). Glutamine phosphoribosylpyrophosphate amidotransferase catalytic and conformational heterogeneity of the pigeon liver enzyme. Biochemistry, 9, 1498-1505.

Rowe, P. B., and Wyngaarden, J. B. (1968). Glutamine phosphoribosylpyrophosphate amidotransferase. Purification, substructure, amino acid composition and absorption spectra. J. biol. Chem., 243, 6373-6383.

Schulman, J. D., Greene, M. L., Fujimoto, W. Y., and Seegmiller, J. E. (1971). Adenine therapy for Lesch-Nyhan syndrome. Pediat. Res., 5, 77-82.

Scott, J. T., Dixon, A. St. J., and Bywaters, E. G. L. (1964). Association of hyperuricaemia and gout with hyperparathyroidism. Brit. med. J., 1, 1070-1073.

Seegmiller, J. E. (1968). Lesch-Nyhan syndrome: management and treatment (with Discussion). Fed. Proc., 27, 1097-1104.

Seegmiller, J. E., and Frazier, P. D. (1966). Biochemical considerations of the renal damage of gout. Ann. rheum. Dis., 25, 668-672.

Seegmiller, J. E., Grayzel, A. I., Howell, R. R., and Plato, C. (1962). The renal excretion of uric acid in gout. $J$. clin. Invest., 41, 1094-1098.

Seegmiller, J. E., Grayzel, A. I., Laster, L., and Liddle, L. (1961). Uric acid production in gout. J. clin. Invest., 40, 13041314.

Seegmiller, J. E., Rosenbloom, F., and Kelley, W. N. (1967), Enzyme defect associated with a sex-linked human neurological disorder and excessive purine synthesis. Science, 155, 1682-1684.

Silvers, D. N., Cox, R. P., Balis, M. E., and Dancis, J. (1972). Detection of the heterozygote in Lesch-Nyhan disease by hair-root analysis. New Engl. J. Med., 286, 390-395.

Simkin, P. A., Skeith, M. D., and Healey, L. A. (1973). Suppression of uric acid secretion in a patient with renal hypouricemia. (Abstr.) Israel J. med. Sci., 9, 1113.

Sperling, O., Persky-Brosh, S., Boer, P., Kanarek, E., and De Vries, A. (1973). Human erythrocyte phosphoribosylpyrophosphate synthetase mutationally altered in regulatory properties. Biochem. Med., 7, 389-395.

Sperling, O., Eilam, G., Persky-Brosh, S., and De Veries, A. (1972). Accelerated erythrocyte 5-phosphoribosyl-1-pyrophosphate synthesis. A familial abnormality associated with excessive uric acid production and gout. Biochem. Med., 6, 310-316.

Steele, T. H. (1971). Control of uric acid excretion. New Engl. J. Med., 284, 1193-1196.

Stetten, M. R., and Taft, H. L. (1964). Metabolism of inorganic pyrophosphate. II. The probable identity of microsomal inorganic pyrophosphatase, pyrophosphate phosphotransferase, and glucose 6-phosphatase. J. biol. Chem., 239, 40414046.

Strand, L. J., Felsher, B. F., Redeker, A. G., and Marver, H. S. (1970). Heme biosynthesis in intermittent acute porphyria: decreased hepatic conversion of porphobilinogen to porphyrins and increased deltaaminolevulinic acid synthetase activity. Proc. nat. Acad. Sci. (Wash.), 67, 1315-1320.

Subak-Sharpe, J. H. (1969). Metabolic cooperation between cells. In Homeostatic Regulators: A Ciba Foundation Symposium edited by G. E. W. Wolstenholme and J. Knight, pp. 276-290, Churchill, London.

Sweetman, L., and Nyhan, W. L. (1970). Detailed comparison of the urinary excretion of purines in a patient with the LeschNyhan syndrome and a control subject. Biochem. Med., 4, 121-134.

Talbott, J. H., and Terplan, K. L. (1960). The kidney in goui. Medicine (Baltimore) 39, 405-467.

Watts, R. W. E. (1966). Uric acid production with particular reference to the role of xanthine oxidase and its inhibition. Proc. roy. Soc. Med., 59, 287-291.

Watts, R. W. E. (1972). Disorders of purine metabolism. In Eighth Symposium on Advanced Medicine, edited by G. Neale, pp. 285 307. Pitman and Journal of the Royal College of Physicians, London.

Watts, R. W. E. (1974a). Determination of uric acid in blood and in urine. Ann. clin. Biochem., 11, 103-111. 
Watts, R. W. E. (1974b). Unpublished.

Watts, R. W. E., McKeran, R. O., Brown, E., Andrews, T. M., and Griffiths, M. I. (1974). Clinical and biochemical studies on the treatment of the Lesch-Nyhan syndrome. Arch. Dis. Child., in press.)

Wilson, D. M., and Tapia, H. R. (1973). Oxypurine excretion in a large family with xanthinuria. (Abstr.) Israel J. med. Sci., $9,1118$.

Wood, A. W., and Seegmiller, J. E. (1973). Properties of 5-phosphoribosyl-1-pyrophosphate amidotransferase from human lym- phoblasts. J. biol. Chem., 248, 138-143.

Yü, T. F., Balis, M. E., Krenitsky, T. A., Dancis, J., Silvers, D. N. Elion, G. B., and Gutman, A. B. (1972). Rarity of X-linked partial hypoxanthine-guanine phosphoribosyltransferase deficiency in a large gouty population. Ann. intern. Med., 76, 255-264.

Yü, T. F., Sirota, J. H., Berger, L., Halpern, M., and Gutman, A. B. (1957). Effect of sodium lactate infusion on urate clearance in man. Proc. Soc. exp. Biol. (N.Y.), 96, 809-813. 